\title{
Rising to the challenge? Inter-individual variation of the androgen response to social interactions in cichlid fish
}

\author{
Ana S. Félix ${ }^{\mathrm{a}, \mathrm{b}}$, António Roleira ${ }^{\mathrm{a}}$, Rui F. Oliveira ${ }^{\mathrm{a}, \mathrm{b}, \mathrm{c}, *}$ \\ a ISPA - Instituto Universitário, Rua Jardim do Tabaco 34, 1149-041 Lisboa, Portugal \\ ${ }^{\mathrm{b}}$ Instituto Gulbenkian de Ciência, Rua da Quinta Grande 6, 2780-156 Oeiras, Portugal \\ ${ }^{\mathrm{c}}$ Champalimaud Neuroscience Programme, Champalimaud Centre for the Unknown, Avenida Brasília, 1400-038 Lisboa, Portugal
}

\section{A R T I C L E I N F O}

\section{Keywords:}

Mozambique tilapia

Challenge hypothesis

Androgens

Temporal pattern

Inter-individual variation

Personality

\begin{abstract}
A B S T R A C T
The Challenge Hypothesis (Wingfield et al. Am. Nat. 136, 829-846) aims to explain the complex relationship between androgens and social interactions. Despite its well acceptance in the behavioral endocrinology literature, several studies have failed to found an androgen response to staged social interactions. Possible reasons for these inconsistencies are the use of single sampling points that may miss the response peak, and the occurrence of inter-individual variability in the androgen response to social interactions. In this study we addressed these two possible confounding factors by characterizing the temporal pattern of the androgen response to social interactions in the African cichlid, Oreochromis mossambicus, and relating it to inter-individual variation in terms of the individual scope for androgen response (i.e. the difference between baseline and maximum physiological levels for each fish) and behavioral types. We found that the androgen response to territorial intrusions varies between individuals and is related to their scope for response. Individuals that have a lower scope for androgen response did not increase androgens after a territorial intrusion but were more aggressive and exploratory. In contrast males with a higher scope for response had fewer aggressive and exploratory behaviors and exhibited two peaks of KT, an early response $2-15 \mathrm{~min}$ after the interaction and a late response at $60-90 \mathrm{~min}$ post-interaction. Given that the pharmacological challenge of the Hypothalamic-Pituitary-Gonad axis only elicits the late response, we suggest that these two peaks may be regulated by different physiological mechanisms, with the early response being mediated by direct brain-gonad neural pathways. In summary, we suggest that determining the temporal pattern of the androgen response to social interactions and considering inter-individual variation may be the key to understanding the contradictory results of the Challenge Hypothesis.
\end{abstract}

\section{Introduction}

Almost 30 years ago, Wingfield et al. (1990) introduced the Challenge Hypothesis as a framework to study the androgen response to social interactions. Since then, their essay has been a landmark for behavioral endocrinologists that aim to understand the complex relationship between androgens and the social environment. According to this model, constitutive androgen circulating levels (constitutive baseline, $a$ ) occur during the non-breeding phase, while at the onset of the breeding season they increase up to the concentration needed for the full development of the gonads, the development of secondary sex characteristics and for the expression of reproductive behaviors (breeding baseline, b) (Wingfield et al., 1990). Then, androgens can further rise above the breeding baseline and reach a physiological maximum $(c)$ in response to social interactions, either with males or with sexually receptive females (Wingfield et al., 1990). Thus, the social interactions of an individual will determine its androgen levels. Moreover, the Challenge Hypothesis generates a number of predictions regarding the seasonal patterns of androgen social responsiveness [quantified by the ratio $(c-a) /(b-a)$ ] in seasonal breeders according to the mating system and parental care type of the species. For example, since androgens interfere with paternal care, males from species that provide parental care should have low androgen levels during parental phase that rise in response to male or female interactions (high androgen responsiveness), whereas species in which males invest less in parental care are expected to have higher androgen levels but lower androgen responsiveness to social interactions (Wingfield et al., 1990).

Although the Challenge Hypothesis was initially proposed based on comparative data from bird species, it has been extensively tested across all vertebrate taxa, including teleost fish (Hirschenhauser and

\footnotetext{
* Corresponding author at: ISPA - Instituto Universitário, Rua Jardim do Tabaco 34, 1149-041 Lisboa, Portugal.

E-mail address: ruiol@ispa.pt (R.F. Oliveira).
} 
Oliveira, 2006; Hirschenhauser et al., 2004; Oliveira, 2004). Overall, the predictions regarding the seasonal variations in androgen levels have been confirmed (Goymann et al., 2007), but many of the published studies, even in birds, failed to observe the predicted androgen response to simulated social challenges (e.g., rodents: Fuxjager et al., 2010; dwarf mongooses: Creel et al., 1993; amphibians: de Assis et al., 2012; fish: Ros et al., 2014; reptiles: Baird et al., 2014; birds: Moore et al., 2004). Recently, it has been argued that one possible explanation for these contradictions is the fact that most studies so far have focused on androgen responses to male-male interactions (i.e. territorial intrusions or staged fights), and that male-female interactions would contribute more to the observed seasonal patterns (Goymann et al., 2019). However, there are other possible explanations for the failure in detecting the androgen response to social interactions, namely using inappropriate sampling points that miss the peak of response due to lack of knowledge on the time courses of the response for each studied species and the occurrence of inter-individual variability in androgen response associated to behavioral variation (e.g. personality types).

Indeed, the temporal dynamics of the androgen response to social interactions has only been studied in few species and there is significant variation in the observed patterns. For instance, the response of testosterone in males to the presence of a receptive females peaks between $30 \mathrm{~min}$ and $60 \mathrm{~min}$ after exposure in male Sprague-Dawley rats (Kamel and Frankel, 1978), whereas in male mice (CBA strain) it peaks at $20 \mathrm{~min}$ in Winter and at $40 \mathrm{~min}$ in Summer (Amstislavskaya and Popova, 2004). Similarly, aggressive encounters elicit a testosterone peak in winners $45 \mathrm{~min}$ after a fight in California mice (Peromyscus californicus) (Marler et al., 2005) and at 60 min post-fight in swordtail fish (Xiphophorus helleri) (Hannes et al., 1984). Thus, without knowing the temporal dynamics of the androgen response to social interactions for their studied species and using reported sampling points for other species, some studies with negative results may have simply missed the androgen peak they were aiming to characterize, highlighting the need for the characterization of the time course of the response for each species.

On the other hand, few studies account for inter-individual variation in hormonal responses. Usually, comparisons of androgen responsiveness are made between species averaging all sampled individuals (e.g., Goymann, 2009; Hirschenhauser et al., 2003, 2004; Oliveira et al., 2002; Wingfield et al., 1990), ignoring the possible occurrence of alternative phenotypes that may cancel each other in the sample. By 1987, (Bennett, 1987) already emphasized the need to focus on biological differences among individuals and to shift our attention from the 'tyranny of the Golden Mean', particularly in physiological studies. Indeed, although the function and mechanisms that underpin individual variation are not fully understood, several authors have highlighted the importance of this issue in the context of endocrinology (Hau and Goymann, 2015; Kempenaers et al., 2008; Williams, 2008). Actually, for the same population, variation in hormone levels among individuals is quite impressive (e.g. up to two orders of magnitude, (Kempenaers et al., 2008; see also Williams, 2008) and may be related to fitness (Hau and Goymann, 2015). Such differences between individuals in terms of baseline and/or maximum levels could influence the scope for androgen responsiveness leading to inter-individual differences within the same species.

Moreover, inter-individual variation of the androgen response can be related to intrinsic psychological features, such as observed in the stress response (Koolhaas et al., 1999). In recent years, a considerable amount of literature has been published on inter-individual variation in behavior profiles. Contrasting patterns are observed whenever individuals behave and interact with their environment. Several definitions with somewhat similar meanings have been proposed for consistent differences between individuals. The term 'temperament' (or personality) is generally understood as the consistency of behavioral differences between individuals over time and across situations (Caramachi et al., 2013; Réale et al., 2007). Distinct behavioral traits (or axes) have been proposed: shyness-boldness (in risky situations, e.g. predator), exploration-avoidance (in new situations), activity (in nonrisky and non-novel situations), aggressiveness (towards conspecifics) and sociability (Réale et al., 2007; Sih et al., 2004). It is worth noting that, in a population, the distribution of individuals along these axes is expected to follow a continuum, rather than a bimodal distribution (Réale et al., 2007). If a set of behavioral traits correlate between each other, one may define it as a 'behavioral syndrome' (Bell, 2007; Sih et al., 2004), which could mean that the traits are regulated by a common neuroendocrine, genetic or neurobiological mechanism (Coppens et al., 2010; Sih et al., 2004). For instance, the best known behavioral syndrome is the proactive-reactive syndrome, studied in the context of stress research to distinguish animals with opposing stresscoping styles (see, for example, Coppens et al., 2010; Koolhaas et al., 1999; Øverli et al., 2007; Young et al., 2011). Proactive individuals are simultaneously bolder, more aggressive and active in response to challenges, show higher exploration rates and, in general, a low Hypothalamus-Pituitary-Adrenals (HPA) axis activity and high sympathetic reactivity. In contrast, reactive individuals seem consistently shy, less aggressive and active, usually freeze in stressful situations and have higher HPA axis and lower sympathetic responses (Koolhaas et al., 1999).

The aim of our study is to characterize the temporal pattern of the androgen response to social (male-male) interactions, taking into account the scope for response of each individual and to relate it to interindividual variation in behavior profiles. For this purpose, we studied Mozambique tilapia, Oreochromis mossambicus, a freshwater fish with a lek-mating system where breeding (dominant) males, which do not show parental care (Fryer and Iles, 1972), aggregate densely in mating territories, where they dig and defend spawning pits (Oliveira and Almada, 1998). A first longitudinal study of weekly territorial challenges followed by androgen sampling at different post-challenge time points (Social challenge experiment), was conducted to characterize the time course curve for each animal. A second longitudinal study (Physiological challenge experiment) was conducted to characterize the time course of the androgen response to a physiological challenge (GnRH injection), Our goal was to compare temporal circulating androgen levels obtained in response to social interactions and those elicited by Hypothalamus-Pituitary-Gonads (HPG) axis stimulation to assess the involvement of the HPG in the observed androgen response to social interactions.

\section{Materials and methods}

\subsection{Animals and housing}

O. mossambicus adult fish from a stock held at ISPA were used in this experiment. Fish were maintained in glass tanks $(120 \times 40 \times 50 \mathrm{~cm}$, $2401)$ with a fine gravel substrate. Each tank was supplied with a double filtering system (gravel and external biofilter) and continuous aeration. Water quality was analized twice per month for nitrites (0.2-0.5 ppm), ammonia (<0.5 ppm, Pallintest kit) and $\mathrm{pH}$ (6.0-6.2). Fish were kept at a temperature of $26 \pm 2{ }^{\circ} \mathrm{C}$, a $12 \mathrm{~L}: 12 \mathrm{D}$ photoperiod, and fed with commercial cichlid floating sticks. O. mossambicus males present two distinct phenotypes: dominants are usually larger, dark colored, establish territories and attract females; while subordinates have a silver color pattern similar to females and fail to establish territories (Oliveira and Almada, 1998). Thirty-six focal dominant males (2.5-3 years old) were used for the experiments described below. Males' social status was monitored several times per week and territorial males were identified by nuptial black coloration and exhibition for at least 1 week of reproductive behavior, including territorial defense and digging of a spawning pit in the substrate (Oliveira and Almada, 1996). 

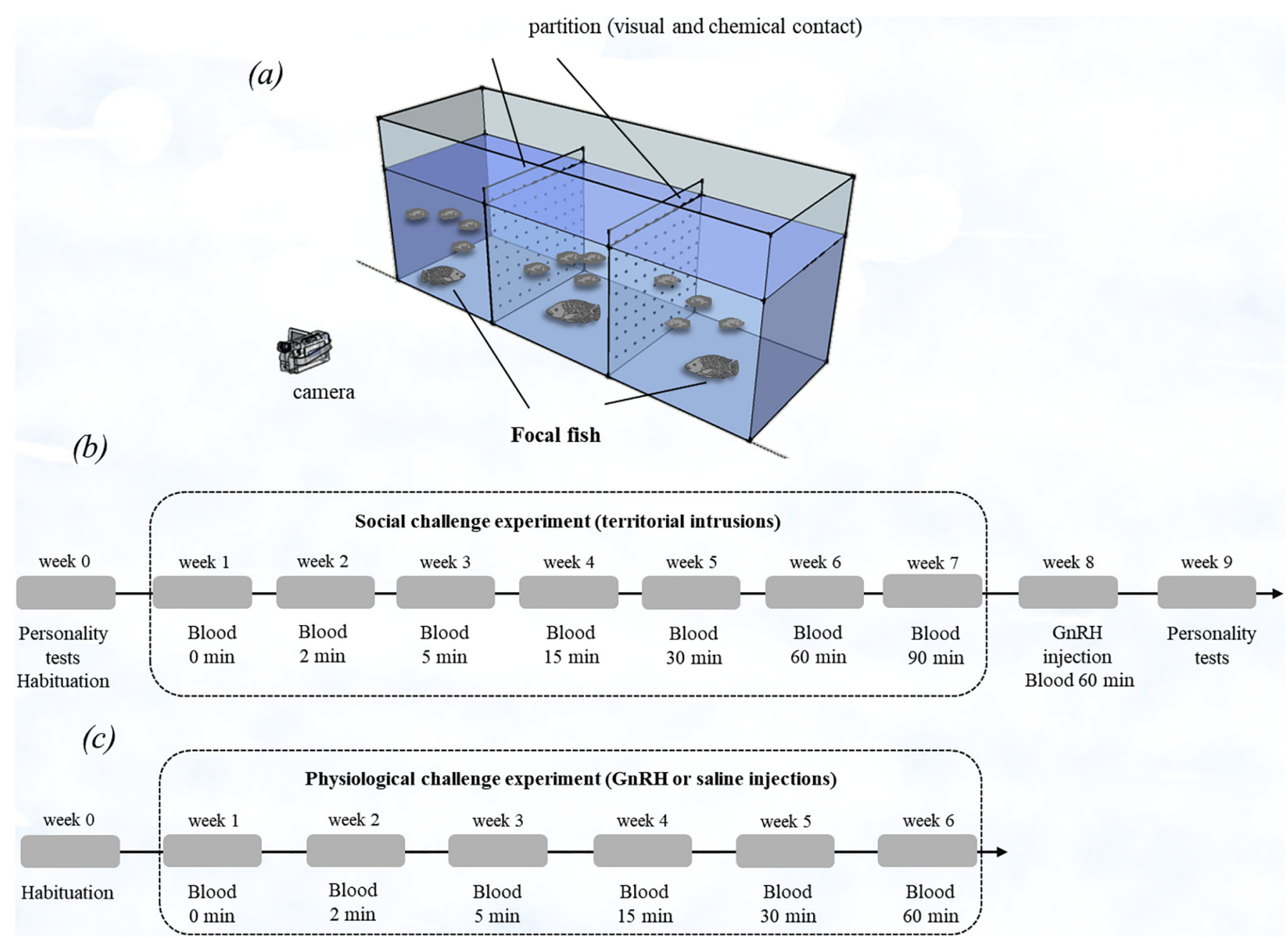

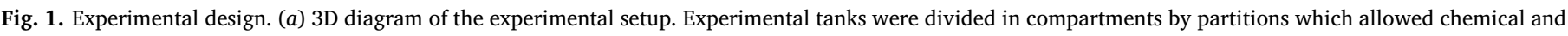

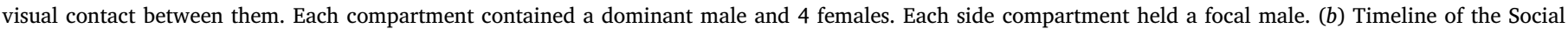

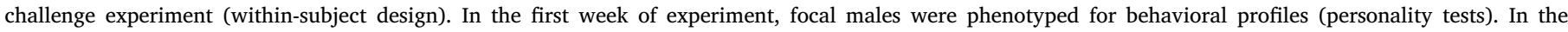

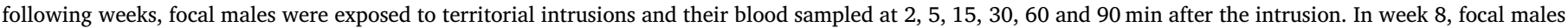

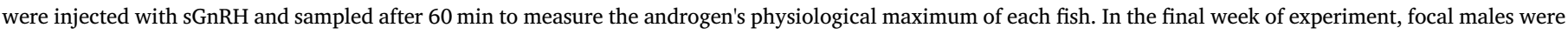

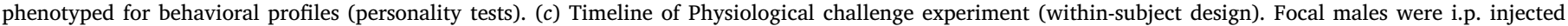

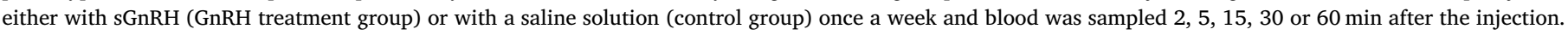

\subsection{Social challenge experiment}

\subsubsection{Experimental setup}

Twenty focal dominant males (mean body mass \pm SEM: $48.03 \mathrm{~g} \pm 1.99 \mathrm{~g} ;$ mean standard length \pm SEM: $11.23 \mathrm{~cm} \pm$ $0.16 \mathrm{~cm}$ ) were phenotyped for their behavioral profile (see below: personality tests), lightly anaesthetized (MS-222, Pharmaq; 300 ppm) to be weighed and measured, and then introduced into experimental tanks (Fig. 1). Each experimental tank $(40 \times 50 \times 120 \mathrm{~cm})$ was divided into 3 compartments with transparent and holed partitions so that chemical and visual contact was possible between compartments. Each compartment contained a dominant male and 4 females. Each side compartment held a focal male. Hence, our experimental setup allowed focal males to interact with other males and females in a simulated semi-natural environment. After 1 week of habituation, focal males were allowed to interact with a male (see below) introduced to their compartment. The intruder male was removed $3 \mathrm{~min}$ after the first aggressive behavior of the focal male towards the intruder. The experiment was run for several weeks to obtain several sampling time points after intrusion. Focal males were randomly removed from the tank at $2,5,15,30,60$ or 90 min after intrusion to collect blood and returned to the experimental tank. A sampling time point of $0 \mathrm{~min}$ corresponds to a week where there was no intrusion. Intruder males were isolated individually also in experimental tanks with 4 females per compartment; they were also territorial males but selected from different stock tanks from those of focal males. Focal males were always larger than intruders (mean body mass \pm SEM: $25.31 \mathrm{~g} \pm 0.96 \mathrm{~g}$; mean standard length \pm SEM: $9.07 \mathrm{~cm} \pm 0.14 \mathrm{~cm}$ ) to ensure the focal male's social advantage. Focal males were subjected to a different intruder each week to control for possible familiarity cues and promote more aggressiveness from focal fish towards stranger intruders (Aires et al., 2015). Interactions between focal and intruder males were video recorded for subsequent behavioral analysis. In the next-to-last week of experiment, focal males were injected with sGnRH $(1000 \mu \mathrm{g} / \mathrm{kg}$; sGnRH analog, (Des-Gly ${ }^{10}$, D-Ala $^{6}$, Pro-NHEt ${ }^{9}$ )-LHRH (salmon); Bachem \#H7525) and sampled after $60 \mathrm{~min}$ to measure the maximum physiological level of each male's androgens. This procedure followed the proposed use of GnRH challenges to estimate maximum physiological levels in the scope of testing the challenge hypothesis (e.g., Apfelbeck and Goymann, 2011). In the final week of experiment, focal males were phenotyped for behavioral profiles (personality tests) using the same behavioral protocol that was used before the start of the experiment to ascertain trait consistency over time, a main requisite of personality. To reduce behavioral or hormonal fluctuations associated with natural 

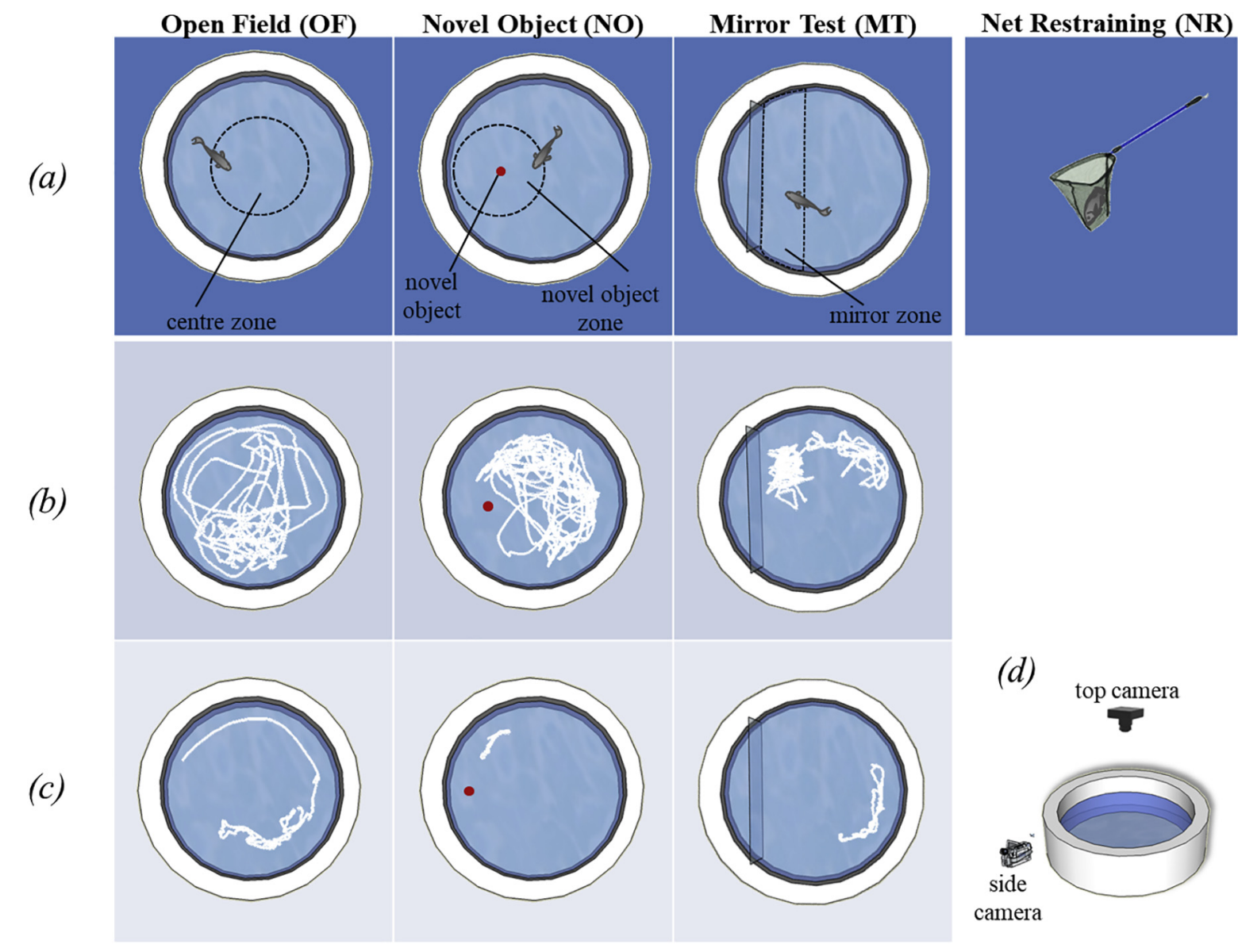

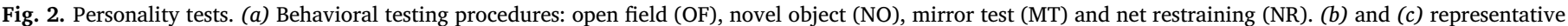

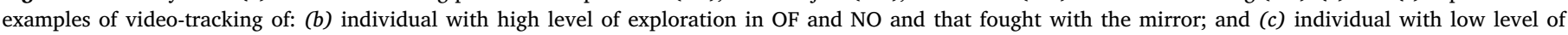
exploration in $\mathrm{OF}$ and $\mathrm{NO}$ and that did not fight with the mirror. (d) 3D diagram of the experimental arena.

circadian rhythm, personality tests were always conducted in the afternoon, while the territorial intrusions were always conducted in the morning.

sGnRH dose was selected based on a dose-response pilot experiment where four different doses and a saline control were tested in male fish. We selected the dose that produced the highest significant increase in circulating androgens above baseline levels (Supplementary Fig. S1).

\subsubsection{Personality tests}

To determine if the androgen response to social interaction is related to behavioral types, we tested individuals on two personality dimensions: exploration-avoidance and aggressiveness (Réale et al., 2007). The focal male was subjected twice (in the first and the last week of the main experiment, see above) to a battery of behavioral tests to assess individual variability and trait consistency. In each session, the focal male was exposed to 4 behavioral tests: (1) open field, (2) novel object, (3) mirror test and (4) net restraining (Fig. 2). Tests were performed consecutively in the same order, but the order of males used in each session was random. The experimental arena consisted on an unfamiliar circular white tank (external diameter: $54 \mathrm{~cm}$; filled to a depth of $12 \mathrm{~cm} ; 201$ of water) with a webcam (Logitech webcam C170) placed overhead for a top-down view. A video camera (Sony DCRSR58E) was placed on the side to enable better discrimination of aggressive behaviors in the mirror test. To minimize disturbance from the surroundings, opaque divisions were placed around the arena. The experimental arena was cleaned at the end of each individual session and the water was replaced with clean maturated water.

Open Field Test (OF) - The male was carefully placed in the arena.
After $30 \mathrm{~s}$ of acclimation, the test phase was initiated and the male was tracked using commercial video tracking software (EthoVision ${ }^{\circledR}$ XT 8.0, Noldus Inc. the Netherlands). Two zones were defined for assessing thigmotaxis (a wall-seeking spatial strategy associated with anxiety, (Champagne et al., 2010) and exploratory behavior in a novel but limited environment: a $10 \mathrm{~cm}$ outer zone (near the arena walls) and the remaining inner area as the centre zone. The following behaviors were recorded for $10 \mathrm{~min}$ : total time in movement, total distance moved, total time spent in the centre zone of the arena, latency to enter the centre zone, number of times spent in the centre zone of the arena, and distance moved in the centre zone. Males that never entered the centre zone were given a maximum latency of $600 \mathrm{~s}$.

Novel Object Test (NO) - Immediately after the OF assay, a weighted red object was introduced in the arena using a fishing line. To keep the object novel, males were presented with a red Lego brick $(3 \times 3 \times 3 \mathrm{~cm})$ in one trial and a red ball of similar dimensions $(4 \mathrm{~cm}$ diameter) in the other trial. This test was conducted to estimate neophobia/neophilia behavior, a particular dimension of explorationavoidance temperament trait (Réale et al., 2007). Two zones were defined for assessing behavioral measures: the novel object zone was a circular $10 \mathrm{~cm}$ radius zone around the object; the remaining area. The following behaviors were recorded for $10 \mathrm{~min}$ : total time in movement, total distance moved, total time spent in the novel object zone, latency to enter the novel object zone, number of times spent in the novel object zone and distance moved in the novel object zone. Males that never entered the novel object zone were given a maximum latency of $600 \mathrm{~s}$.

Mirror Test (MT) - At the end of the NO, the novel object was gently removed using the fishing line. The male was given 2 min to settle, then 
a mirror (dimension: $21 \times 30 \mathrm{~cm}$ ) was placed in the arena leant in a way that prevented males from going behind it during the trial. Since fish do not recognize themselves in mirror, they fight their own image as if it is a conspecific intruder (Oliveira et al., 2005). This test was conducted to assess the male's agonistic reaction in a standardized assay. Two zones were defined to obtain behavioral measures: the mirror zone was a $10 \mathrm{~cm}$-width area near the mirror; the remaining area. The following behaviors were recorded for $5 \mathrm{~min}$ : total time in movement, total distance moved, total time spent in the mirror zone, latency to enter the mirror zone, number of times spent in the mirror zone and distance moved in the mirror zone. Additionally, the number and duration of aggressive behaviors (lateral displays, frontal displays, bites, tail beating) and latency to attack were analyzed using Observer XT software (Noldus technology, version 5, Netherlands). Males that never entered the mirror zone were given a maximum latency of $300 \mathrm{~s}$.

Net Restraining Test (NR) - At the end of the MT, the male was held in a net, out of water, for $1 \mathrm{~min}$. The following behaviors were recorded: number of escape attempts and the total time spent in escape attempts. This is an assay that has been used to evaluate escape behavior in other fish species (e.g., gilthead sea bream, Sparus aurata L., in Arends et al., 1999; Castanheira et al., 2013; flatfish Senegalese sole, Solea senegalense, in Silva et al., 2010; Nile tilapia, Oreochromis niloticus, in Martins et al., 2011).

\subsection{Physiological challenge experiment}

This study was conducted to characterize the time course of the androgen response to a $\mathrm{GnRH}$ challenge. On the first day of experiment, focal males were lightly anaesthetized (MS-222, Pharmaq; $300 \mathrm{ppm}$ ) to be weighed and measured, and then introduced into the same experimental tanks used in the Social Challenge Experiment (Fig. 1). Sixteen focal dominant males (mean body mass \pm SEM: $51.65 \mathrm{~g} \pm 2.93 \mathrm{~g}$; mean standard length \pm SEM: $11.80 \mathrm{~cm} \pm 0.22 \mathrm{~cm}$ ) were used. Focal males were arbitrarily assigned to the GnRH treatment group $(n=8)$ or to the control group $(n=8)$. All males had intraperitoneal injections once a week, treatment group (G group) with a GnRH analog (100 $\mu$ g/ $\mathrm{kg}$ ), controls (V group) with a saline vehicle solution $(0.9 \%$ sodium chloride). The experiment was run for several weeks to obtain samples at several time points after the injection. Focal males were randomly removed after $2,5,15,30$ or 60 min after injection to collect blood and returned to the experimental tanks. The sampling time point of $0 \mathrm{~min}$ corresponds to a week where there was no injection.

\subsection{Behavioral observations}

Behavior of focal males during territorial intrusions (main experiment) was analyzed using Observer XT software (Noldus technology, version 5, Netherlands), based on the ethogram provided by Baerends and Baerends-van Roon (1950). Relevant behavioral patterns were identified to measure male aggressiveness towards the intruder, the neighbor or the females (i.e. bites, displays, buttings, chasing, tail beating). Other behaviors (nipping, swimming, floating, courting, glass interactions) were also quantified. We recorded the frequency and latency of the reported behaviors, as well as the attack latency (i.e., time between the beginning of the recording period and the first aggressive behavior). Similarly, for personality tests the aggressive behavior of focal males during the Mirror Test (MT) and the time spent performing escape attempts in the Net Restraining Test (NR) was analyzed using the same software. Other variables measured in the personality tests were obtained with EthoVision XT 8.0 (Noldus Inc. the Netherlands).

\subsection{Blood sampling}

Males were anaesthetized (MS-222, Pharmaq; $450 \mathrm{ppm}$ ) and blood was collected from the caudal vein using heparinized 25-gauge needles. Blood sampling always took place within $4 \mathrm{~min}$ of the induction of anaesthesia to prevent possible effects of handling stress on steroids levels (Foo and Lam, 1993). Blood samples were centrifuged (10 min, $3000 \mathrm{~g}, 4^{\circ} \mathrm{C}$ ) and plasma was stored at $-20^{\circ} \mathrm{C}$ until further processing.

\subsection{Hormone assays}

11-ketotestosterone (KT), testosterone (T) and cortisol (F) were extracted from plasma samples by adding diethyl-ether (Merck). Samples were then agitated for $20 \mathrm{~min}$, centrifuged $\left(5 \mathrm{~min}, 163 \mathrm{~g}, 4^{\circ} \mathrm{C}\right.$ ) for phase separation and kept at $-80^{\circ} \mathrm{C}$ for $15 \mathrm{~min}$ to freeze the water phase and separate the ether fraction (containing the free steroid). This process was repeated twice to obtain higher extraction efficiency. The ether fraction was evaporated with a Speedvac (Savant SC1101) and the dried organic phase was re-suspended in phosphate buffer. Steroid concentrations were measured by radioimmunoassay using a testosterone antibody from Research Diagnostics Inc. (\#WLI-T3003, rabbit anti-testosterone) and cortisol antibody from Fitzgerald (\#20-CR-50, rabbit anti-cortisol). The antibody used for the 11-ketotestosterone assay was kindly donated by D. E. Kime and the corresponding specificity table was published in Kime and Manning (1982). Reactive markers used in radioimmunoassays for testosterone and cortisol were from Amersham Biosciences ([1,2,6,7-3H] Testosterone, \#TRK402-250 $\mu \mathrm{Ci}$; [1,2,6,7-3H] Cortisol, \#TRK407-250 $\mu \mathrm{Ci}$ ) while 11-ketotestosterone marker was produced in-house from marked cortisol (Kime and Manning, 1982). Samples collected from each male were run in the same assay. Inter-assay variabilities were $7.9 \%$ for KT, $8.0 \%$ for T and $11.9 \%$ for F. Intra-assay variation coefficients were $8.0 \%, 4.9 \%, 4.7 \%$, $0.4 \%$ and $5.2 \%$ for KT; $11.5 \%, 5.5 \%, 5.1,4.3 \%$ and $8.8 \%$ for T; $4.9 \%$ and $11.2 \%$ for $\mathrm{F}$.

\subsection{Data analysis}

Normality of the data was tested by analyzing skewness and kurtosis values (Kline, 1998) and running Shapiro-Wilk tests. If necessary, variables were $\log$ transformed to meet parametric assumptions. Homocedascity was confirmed with Levene's test.

The androgen scope of each individual, defined as the androgen responsiveness score, was assessed by dividing KT baseline levels for KT physiological maximum (GnRH induced levels). Individuals that had values above the mean were defined as low androgen responders (LR), because they had a lower scope for response; while those that had an androgen responsiveness score below the mean were considered the high androgen responders (HR) because they had a greater scope of response. We used KT in this calculation since it has been reported as the main androgen in teleost fish (Borg, 1994) and found to respond to social interactions in this species (Hirschenhauser et al., 2004). For the Social challenge experiment, hormone levels (KT, T and F) were analyzed using a Linear Mixed Model (LMM) with time and type of androgen response (HR vs LR) as fixed effects and focal male as a random effect. Planned comparisons were used to compare steroid levels relative to baseline and the $p$-values were adjusted for multiple testing using the Benjamini and Hochberg (1995) procedure.

Plots of residuals, fitted values and estimated random effects were used to confirm assumptions of LMM.

Body condition index in the beginning and at the end of the experiment was calculated for each male by dividing its actual weight by its expected weight. Expected weight was assessed by the weight-length relationship obtained in a field study for O. mossambicus (Silva, 1985). $t$ tests were used to compare body mass, body size and body condition index for the two groups (LR and HR males).

We measured repeatability of behavioral variables, for which we obtained multiple measurements (personality tests and territorial intrusions). Repeatability, more generally referred to as the intra-class correlation (ICC), is defined as the proportion of phenotypic variation explained by differences between individuals (Dingemanse and Dochtermann, 2013; Lessells and Boag, 1987): Repeatability $=V_{\text {IND }}$ / 
(a)

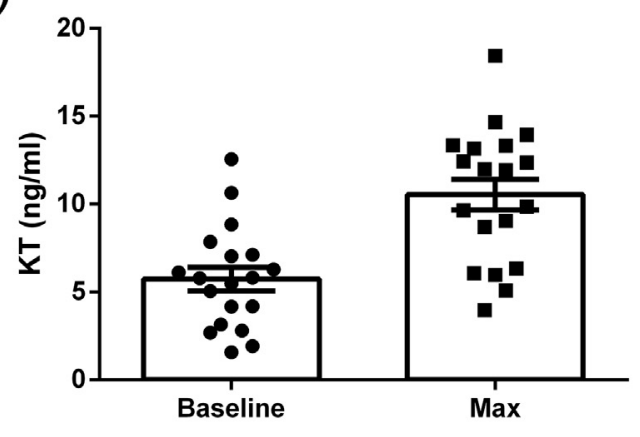

(b)

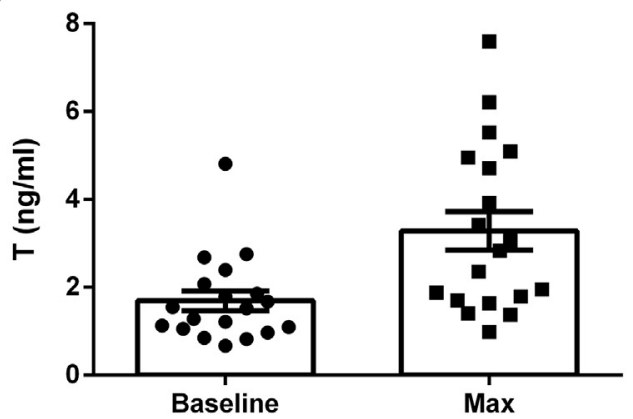

(c)

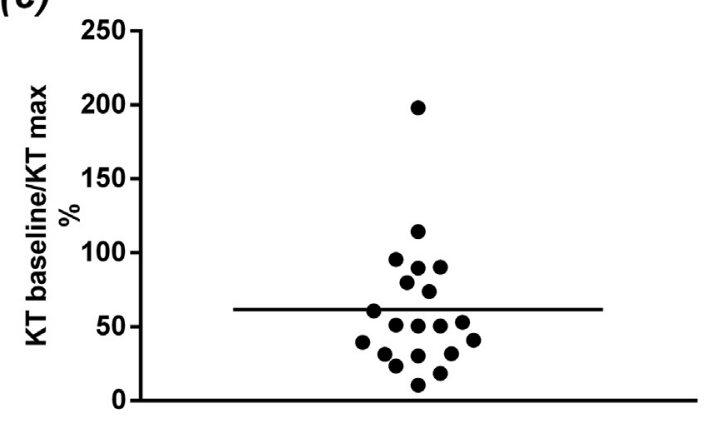

(d)

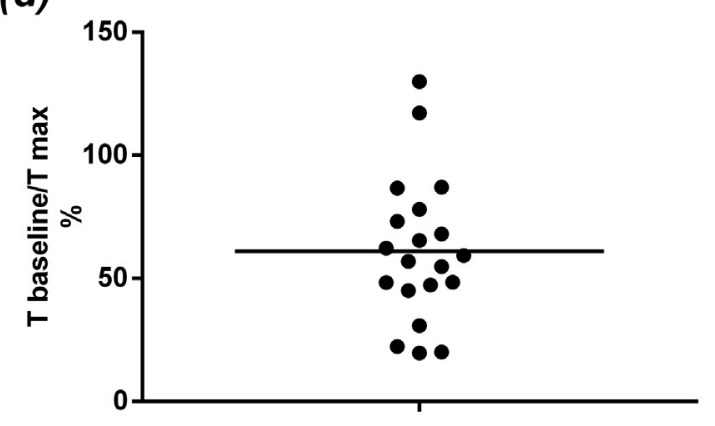

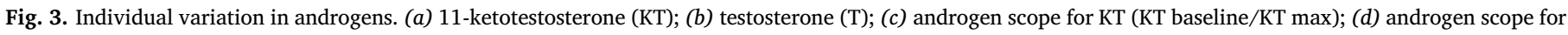

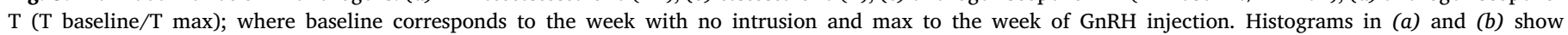
mean \pm standard error of the mean (SEM), in (c) and (d) the line shows the mean. Individual values shown as symbols.

$V_{P}$, where $V_{P}=V_{I N D}+V_{e}$ is the phenotypic variation, composed of the between-individual variance $V_{\text {IND }}$ and the within- individual variance $\mathrm{V}_{\mathrm{e}}$. $\mathrm{V}_{\mathrm{e}}$ represents the 'residual error' due to errors in measurements and general environmental variance. On the other hand, repeatability aims to measure the total variation that is reproducible, that is, the consistency of each trait in the population, allowing comparison across studies for the same trait and across traits in the same study (Dingemanse and Dochtermann, 2013; Harrison et al., 2018). To verify that behavioral responses reflected personality traits, we used the rtpR package (Stoffel et al., 2017) to calculate repeatability. With this package, uncertainty is measured via parametric bootstrapping and likelihood ratio tests are used for significance testing. The number of parametric bootstrap iterations for confidence interval estimation and statistical significance was set to 1000 . We have not calculated repeatabilities for variables accounting for aggressive behaviors in the Mirror Test since in the second trial, none of the males fought with the mirror.

T-tests were used to compare behavioral measures that were repeatable, and assess if any of the behaviors were significantly different for the two groups (LR and HR males).

Behavioral variables of the OF were reduced with Principal Component Analysis (PCA) and different component loadings were obtained with the variable principle normalization method. Since variables were preferentially loaded on the first PCA dimension, only one component was selected which described $68.8 \%$ of the variance of behavior on the OF. This PCA component was interpreted as describing males as more or less exploratory (Supplementary Table S1). Behavioral variables of the territorial intrusion experiment were also reduced with PCA and different component loadings were obtained with the variable principle normalization method. The first PCA dimension was loaded with behavioral variables related to aggression towards intruders and females (29.7\% explained variance), while the second component was related to aggression towards the neighbor (18.5\% explained variance)
(Supplementary Table S2). For these PCA analyses we used the average of the behaviors between the trials. A Pearson correlation between PCA scores of the OF and PCA scores of territorial intrusions was used to examine the relationship between exploration and aggression.

For the Physiological challenge experiment, hormone levels were analyzed using a Linear Mixed Model (LMM) with time and treatment (GnRH or saline injected) as fixed effects and focal male as a random effect. Planned comparisons were used to compare steroid levels relative to baseline and the $p$-values were adjusted for multiple testing (Benjamini and Hochberg, 1995).

Effect sizes were computed for LMM tests (omega-squared, $\omega^{2}$ ) and for post-hoc tests (Cohen's d).

Since we were analyzing individual variability we decided not to remove any apparent outliers or extreme values. Degrees of freedom may vary between the analyses due to missing values because of technical problems (i.e. with blood collection, RIA or video recordings).

Statistical analysis was performed using IBM SPSS ${ }^{\circledR}$ statistics v.21, STATISTICA v.10 (StatsoftInc), and R (R Core Team, 2015) with the following packages: nlme (linear mixed model), multcomp (planned comparisons), rtpR (repeatability), sjstats (effect sizes).

\subsection{Ethics statement}

In this study, we have kept aggressive interactions to a short period ( $3 \mathrm{~min}$ ) and no signs of physical injuries were observed during any of the staged interactions. Experimental procedures used in this study were conducted in accordance with the institutional guidelines for the use of animals in experimentation and were approved both by the internal Ethics Committee of ISPA and by the Portuguese Veterinary Authority (Direção Geral de Alimentação e Veterinária, Portugal; permit number 0421/000/000/2013). 


\section{Results}

\subsection{Social challenge experiment}

There was inter-individual variation in baseline levels (KT: 8.0-fold; T: 7.2-fold; F: 39.6-fold), physiological maximum (KT: 4.6-fold; T: 7.7fold) and in the androgen scope (KT: 18.9-fold; T: 6.6-fold) of focal males (Fig. 3). Following this variation, males were grouped into low responders (LR; $n=7$ ) or high responders (HR; $n=13$ ) according to their androgen responsiveness score (see details in Methods). There was no significant variation in body size between LR and HR males ( $t$ $(18)=1.767, p=0.094$ ), but there was in body weight (beginning of experiment: $\mathrm{t}(17)=3.089, \quad \mathrm{p}=0.007$; end of experiment: $\mathrm{t}$ $(18)=2.100, p=0.050)$. Body condition index was also significantly different between LR and HR fish at the beginning $(\mathrm{t}(17)=3.261$; $\mathrm{p}=0.005 ; \quad$ mean (LR) $\pm \mathrm{SE}=69.91 \pm 4.995 ;$ mean (HR) \pm $\mathrm{SE}=59.91 \pm 6.655$ values $)$ and at the end of the experiment $(\mathrm{t}$ $(18)=2.099, \mathrm{p}=0.050$; mean $(\mathrm{LR}) \pm \mathrm{SE}=61.97 \pm 7.004$; mean $(\mathrm{HR}) \pm \mathrm{SE}=55.22 \pm 6.795)$

The levels of KT, T and F changed significantly with time (KT: $\mathrm{F}_{(7,117)}=6.855, \mathrm{p}<0.0001, \mathrm{~T}: \mathrm{F}_{(7,116)}=7.296, \mathrm{p}<0.0001, \mathrm{~F}:$ $\mathrm{F}_{(6,98)}=23.718, \mathrm{p}<0.0001$, Table 1$)$, but were not significantly affected by whether the fish were HR or LR (KT: $F_{1,18}=0.071$, $\mathrm{p}=0.793, \mathrm{~T}: \mathrm{F}_{(1,18)}=0.104, \mathrm{p}=0.751, \mathrm{~F}: \mathrm{F}_{(1,18)}=0.395, \mathrm{p}=0.538$; Table 1). However, the interaction between these factors was significant for $\mathrm{KT}\left(\mathrm{F}_{(7,117)}=2.629, \mathrm{p}=0.015\right.$, Table 1$)$. HR fish had a significant increase above baseline of KT $2 \mathrm{~min}$ and $5 \mathrm{~min}$ and then again at $90 \mathrm{~min}$ after the territorial intrusion (Table 1, Fig. 4a). There was no difference in KT or T in LR fish after territorial intrusions (Table 1, Fig. 4a and b). GnRH injection elicited a significant increase of both androgens only in HR fish (Table 1, Fig. 4a and b). F levels were higher than baseline between $2 \mathrm{~min}$ and $15 \mathrm{~min}$ for LR and between $2 \mathrm{~min}$ and $5 \mathrm{~min}$ for HR (Table 1, Fig. 4c).

For personality tests, only behavioral variables from the Open Field (OF) were significantly repeatable, namely the distance moved in the centre zone, total distance moved and total time in movement, with repeatability scores higher than 0.57 (Supplementary Table S3).

For territorial intrusions, most of the behavioral variables, either aggressive or non-aggressive were significantly repeatable (Supplementary Table S4). The most repeatable behavior was time spent in chases with a score of 0.587 (Supplementary Table S4).

Several repeatable behavior variables differed significantly between LR and HR males. In the OF, the total distance moved was significantly different between males (LR moved more than HR; Table 2). Other behaviors measured in the OF showed a non-significant tendency of LR to move more in the center of the arena and to spend more time in movement than HR (Table 2). During territorial intrusions, the total number of behaviors (measured as a proxy of activity), aggressive behaviors towards both the intruder and the neighbor and the aggressive behaviors towards the intruder were significantly different, with LR displaying a higher number of these behaviors than HR (Table 2). Similarly, aggressive behaviors towards the neighbor show a non-significant trend of LR to be more aggressive than HR (Table 2).

The PCA score of the OF was significantly negatively correlated with

Table 1

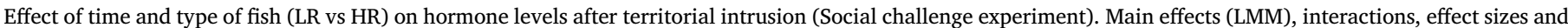
planned comparisons between the baseline and the other time points.

\begin{tabular}{|c|c|c|c|c|c|c|c|c|c|}
\hline \multirow[t]{3}{*}{ Comparisons } & \multirow{2}{*}{\multicolumn{3}{|c|}{ Main effects }} & \multicolumn{6}{|c|}{ Planned comparisons } \\
\hline & & & & \multicolumn{3}{|l|}{ LR } & \multicolumn{3}{|l|}{ HR } \\
\hline & $\mathrm{F}$ & $\mathrm{p}$ & $\omega^{2}$ & $\mathrm{z}$ & $\mathrm{p}$ & $\mathrm{d}$ & $\mathrm{z}$ & $\mathrm{p}$ & $\mathrm{d}$ \\
\hline KT & & & 0.564 & & & & & & \\
\hline Time & 6.855 & $<.0001$ & & & & & & & \\
\hline Fish type & 0.071 & .793 & & & & & & & \\
\hline Time $\times$ fish type & 2.629 & .015 & & & & & & & \\
\hline $0 \mathrm{~min}$ vs $2 \mathrm{~min}$ & & & & -0.869 & .490 & 0.613 & 2.660 & .043 & 0.810 \\
\hline $0 \mathrm{~min}$ vs $5 \mathrm{~min}$ & & & & -0.885 & .490 & 0.392 & 2.579 & .043 & 0.806 \\
\hline $0 \mathrm{~min}$ vs $15 \mathrm{~min}$ & & & & -1.723 & .136 & 0.994 & 1.939 & .123 & 0.734 \\
\hline $0 \mathrm{~min}$ vs $30 \mathrm{~min}$ & & & & -1.708 & .136 & 1.137 & 0.693 & .570 & 1.413 \\
\hline $0 \mathrm{~min}$ vs $60 \mathrm{~min}$ & & & & -1.862 & .125 & 1.186 & 2.281 & .063 & 0.849 \\
\hline $0 \mathrm{~min}$ vs $90 \mathrm{~min}$ & & & & 0.264 & .853 & 0.370 & 2.502 & .043 & 0.942 \\
\hline 0 min vs GnRH & & & & 0.038 & .970 & 0.021 & 6.859 & $<.0001$ & 0.982 \\
\hline $\mathrm{T}$ & & & 0.673 & & & & & & \\
\hline Time & 7.296 & $<.0001$ & & & & & & & \\
\hline Fish type & 0.104 & .751 & & & & & & & \\
\hline Time $\times$ fish type & 1.413 & .207 & & & & & & & \\
\hline $0 \mathrm{~min}$ vs $2 \mathrm{~min}$ & & & & -0.902 & .734 & 0.364 & 0.670 & .782 & 0.227 \\
\hline $0 \mathrm{~min}$ vs $5 \mathrm{~min}$ & & & & -0.701 & .782 & 0.248 & 1.369 & .734 & 0.415 \\
\hline $0 \mathrm{~min}$ vs $15 \mathrm{~min}$ & & & & -0.022 & .996 & 0.007 & 0.946 & .734 & 0.278 \\
\hline $0 \mathrm{~min}$ vs $30 \mathrm{~min}$ & & & & -0.548 & .817 & 0.193 & 0.285 & .988 & 0.053 \\
\hline $0 \mathrm{~min}$ vs $60 \mathrm{~min}$ & & & & -0.005 & .996 & 0.002 & 1.144 & .734 & 0.381 \\
\hline $0 \mathrm{~min}$ vs $90 \mathrm{~min}$ & & & & -0.115 & .996 & 1.010 & 2.153 & .219 & 0.745 \\
\hline 0 min vs GnRH & & & & 1.106 & .734 & 0.377 & 6.258 & $<.0001$ & 1.564 \\
\hline $\mathrm{F}$ & & & 0.698 & & & & & & \\
\hline Time & 23.718 & $<.0001$ & & & & & & & \\
\hline Fish type & 0.395 & .538 & & & & & & & \\
\hline Time $\times$ fish type & 1.160 & .334 & & & & & & & \\
\hline $0 \mathrm{~min}$ vs $2 \mathrm{~min}$ & & & & 3.533 & .002 & 1.029 & 7.547 & $<.0001$ & 1.750 \\
\hline $0 \mathrm{~min}$ vs $5 \mathrm{~min}$ & & & & 3.118 & .005 & 1.430 & 3.199 & .005 & 0.956 \\
\hline $0 \mathrm{~min}$ vs $15 \mathrm{~min}$ & & & & 2.330 & .048 & 0.796 & 2.116 & .069 & 1.246 \\
\hline $0 \mathrm{~min}$ vs $30 \mathrm{~min}$ & & & & 0.319 & .750 & 0.036 & 1.002 & .422 & 1.102 \\
\hline $0 \mathrm{~min}$ vs $60 \mathrm{~min}$ & & & & -0.922 & .428 & 0.467 & -0.562 & .627 & 0.098 \\
\hline $0 \mathrm{~min}$ vs $90 \mathrm{~min}$ & & & & -1.451 & .220 & 1.802 & -1.787 & .127 & 0.209 \\
\hline
\end{tabular}

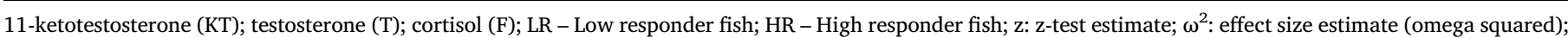
d: effect size estimate (Cohen's d); p: p-value after multiple comparison adjustment; statistically significant values are in bold. 
(a)

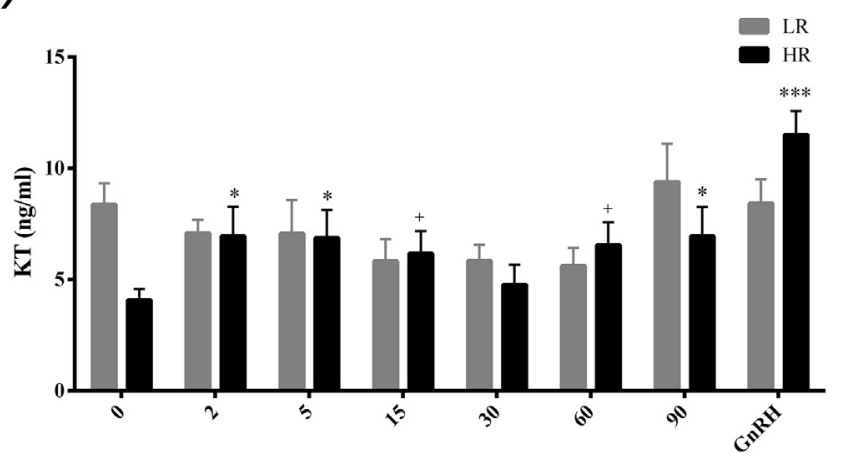

Time (min)

(b)

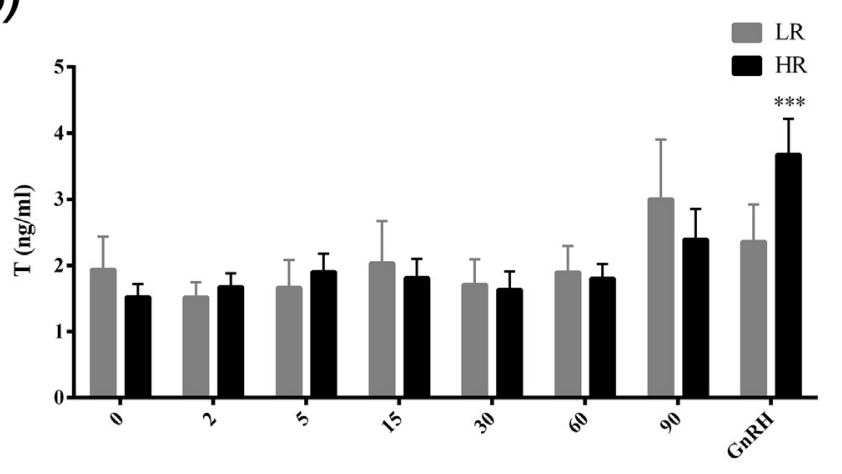

Time (min)

(c)

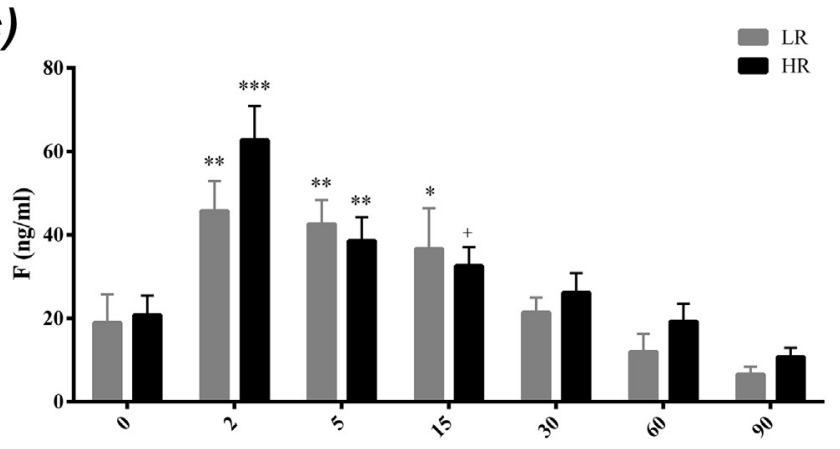

Time (min)

Fig. 4. Temporal pattern of the hormonal response to territorial intrusions for Low Responder (LR) and High Responder (HR) fish (see methods for details) in Social challenge experiment. Values are mean \pm standard error of the mean (SEM). (a) 11-ketotestosterone (KT); (b) testosterone (T); (c) cortisol (F); + non-significant trend $\mathrm{p}<0.10 ;{ }^{*} \mathrm{p}<0.05$; ** $\mathrm{p}<0.01$; *** $\mathrm{p}<0.001$.

the second PCA score of the territorial intrusions $(r=-0.466$, $\mathrm{p}=0.039, \mathrm{n}=20$ ), suggesting that individuals with higher scores of exploratory behavior were less aggressive towards the neighbor.

\subsection{Physiological challenge experiment}

The levels of KT changed significantly with time $\left(\mathrm{F}_{(5,67)}=3.862\right.$, $\mathrm{p}=0.004$, Table 3 ) but were not significantly affected by treatment with GnRH or control (saline) $\left(\mathrm{F}_{(1,14)}=0.462, \mathrm{p}=0.508\right.$, Table 3 ). However, the interaction between these factors was significant $\left(\mathrm{F}_{(5,67)}=9.568, \mathrm{p}<0.0001\right.$, Table 3$)$. The levels of $\mathrm{T}$ changed significantly with time $\left(\mathrm{F}_{(5,68)}=7.851, \mathrm{p}<0.0001\right.$, Table 3$)$ but were not significantly affected by treatment $\left(\mathrm{F}_{(1,14)}=3.380, \mathrm{p}=0.087\right.$, Table 3 ). The interaction between these factors was significant
$\left(\mathrm{F}_{(5,68)}=11.529, \mathrm{p}<0.0001\right.$, Table 3$)$. Fish injected with GnRH significantly decreased KT, 2 min and 5 min after the injection and then significantly increased at $60 \mathrm{~min}$, compared to the baseline (Table 3, Fig. 5a). For the control group, KT significantly decreased $15 \mathrm{~min}$ after the injection and remained below the baseline even after $60 \mathrm{~min}$ (Table 3, Fig. 5a). For T, there was a significant increase of $\mathrm{T}$ only for GnRH-treated group $30 \mathrm{~min}$ and $60 \mathrm{~min}$ time points (Table 3, Fig. 5b).

\section{Discussion}

Our results show that the androgen response to territorial intrusions varies between dominant males of the Mozambique tilapia and is related to their scope for response (i.e. the difference between baseline and maximum physiological levels for each fish). Individuals that have a lower scope for androgen response did not increase androgens after a territorial intrusion but were more aggressive and exploratory. Males with a higher scope for response have fewer aggressive and exploratory behaviors and exhibit two waves of KT response, one soon after the aggressive challenge (2-15 min) and other about an hour later (60-90 min). Moreover, subjecting fish to a GnRH challenge elicits an androgen increase 30-60 min after the injection.

In the case of the Mozambique tilapia, a polygynous species where males do not show parental care, the Challenge Hypothesis predicts a low androgen response to social interactions, when compared to species with other mating systems (Wingfield et al., 1990). We found that androgen responsiveness was rather variable, even though males had the same social rank, since baseline and physiological maximum levels differed largely between individuals. Therefore, males with KT baseline levels very close to their maximum (Low responder fish, LR) were not capable of significantly increasing androgen levels either to social or physiological challenges. Interestingly, other males (High responder fish, HR) had a higher scope for response and exhibited two peaks of KT levels, probably playing different roles. The quick response of KT may be related to the necessity to deal with the ongoing fight, regulating the male's behavior during the interaction (Marler et al., 2005). Another explanation for this short-term response can be a stress-provoked response to intrusion that has been described in acute stress events (e.g. androgen elevation $3 \mathrm{~min}$ after confinement in sockeye salmon, Onchorhynchus nerka: Kubokawa et al., 2001), which is confirmed by the elevated levels of cortisol soon after the social challenge. Several authors have proposed that fast androgen responses may enable swift and flexible behavioral responses to social challenges (Kempenaers et al., 2008; Oliveira, 2004). On the other hand, the delayed KT response suggests its involvement in the modulation of future interactions, possibly as a result of the outcome of the interaction (e.g. winner/loser effects) (Hsu et al., 2011; Oliveira et al., 2009; Oyegbile and Marler, 2005). From an overall perspective, we verified that KT increased in some individuals but decreased in others, hence these changes would cancel out each other at the population level. These results further support the idea that endocrine studies should focus on individual data rather than on the mean value of an heterogeneous group of individuals (Bennett, 1987; Williams, 2008). For instance, in bird breeding populations in the wild male $\mathrm{T}$ levels may vary 200 -fold (e.g. blue tits, Kempenaers et al., 2008; black redstarts, Phoenicurus ochruros, Apfelbeck et al., 2013). Even within the same social status, animals can have distinct endocrine profiles, baseline and environment hormone reactions (e.g., Alcazar et al., 2016; Virgin and Sapolsky, 1992). Moreover, to compare traits or physiological measures obtained in different situations the same individuals should be used in withinsubject designs (Bennett, 1987; Williams, 2008). In addition, not only the magnitude but also the temporal pattern of the androgen response can vary, which means that the variation of response with time for each individual is much more relevant than single 'snapshots' of the hormonal variation (Kempenaers et al., 2008).

Interestingly, our results also show that the scope for response is associated with body condition, with LR males exhibiting a higher body 
Table 2

Statistical values for the differences between behavior of LR and HR fish in personality tests and over the territorial intrusions.

\begin{tabular}{|c|c|c|c|c|c|}
\hline & Mean LR & Mean HR & $t(d f)$ & $\mathrm{p}$ & $\mathrm{d}$ \\
\hline \multicolumn{6}{|l|}{ Open field test } \\
\hline Distance moved in the centre zone & 841.222 & 450.677 & $1.896(18)$ & .074 & 0.834 \\
\hline Total distance moved & 1714.852 & 824.268 & $2.095(18)$ & .050 & 1.000 \\
\hline Total time in movement & 221.362 & 114.180 & $1.994(18)$ & .062 & 0.981 \\
\hline \multicolumn{6}{|l|}{ Territorial intrusions } \\
\hline Total number of aggressive behaviors (males) & 35.090 & 26.400 & $2.550(18)$ & .020 & 1.237 \\
\hline Total time spent in aggressive behaviors (males) & 203.119 & 179.333 & $2.067(18)$ & .053 & 0.928 \\
\hline Total number of aggressive behaviors (intruder) & 28.281 & 21.405 & $2.210(18)$ & .040 & 1.080 \\
\hline Total time spent in aggressive behaviors (intruder) & 171.867 & 152.838 & $1.736(18)$ & .100 & 0.822 \\
\hline Total number of aggressive behaviors (neighbor) & 6.810 & 4.995 & $1.839(18)$ & .082 & 0.609 \\
\hline Total time spent in aggressive behaviors (neighbor) & 31.252 & 26.495 & $0.339(18)$ & .738 & 0.151 \\
\hline Total number of aggressive behaviors (females) & 1.938 & 1.808 & $0.181(18)$ & .858 & 0.091 \\
\hline Total time spent in aggressive behaviors (females) & 3.267 & 1.854 & $0.470(18)$ & .644 & 0.216 \\
\hline Total number of non-aggressive behaviors & 1.457 & 1.764 & $-0.354(18)$ & .727 & 0.160 \\
\hline Total time spent in non-aggressive behaviors & 5.062 & 15.051 & $-1.231(18)$ & .234 & 0.598 \\
\hline Total number of behaviors & 38.486 & 29.972 & $2.518(18)$ & .021 & 1.156 \\
\hline
\end{tabular}

LR - Low responder fish; HR - High responder fish; t: t-test estimate; d: effect size estimate (Cohen's d); p: p-value; statistically significant values are in bold.

condition index than HR males. This finding suggests the occurrence of a trade-off between androgen responses and physical condition, such that individuals that have a low body condition (typically HR) are not able to maintain high levels of androgens, and thus sharply increase androgens when faced with a challenge, whereas, individuals with a good body condition (typically LR) keep their androgen levels high, and when challenged exhibit a low response. This finding is in agreement with previous work which has shown that keeping high levels of androgens is energetically costly, and is also associated to immune-suppression and oncogenic effects (Oliveira, 2004; Wingfield et al., 2001).

At the behavioral level, we found several behaviors to be quite variable between individuals but consistent within individuals. Regarding personality tests, behavior variables were repeatable only in the Open field (OF) test. This demonstrates that exploratory behavior is consistent in this species within a two months interval, even when subjecting males to repetitive behavioral and experimental manipulations. The other tests, Novel Object (NO), Mirror Test (MT) and Net Restraining (NR), seemed to be influenced by the underlying factors and could not be used to characterize consistent behavioral profiles. For example, a lack of consistency across contexts (social vs isolation) of the NO test in this species has already been reported (Galhardo et al., 2012), while a lack of consistency across time has been found for other species (e.g., Gilthead seabream, Sparus aurata: (Castanheira et al., 2013). Supporting consistency of exploratory behavior and not of other traits in other taxa, are long-term personality studies carried in zebrafinches, Taeniopygia guttata, which found fearlessness and exploration the most repeatable traits within and across life phases, contrary to struggling rate (comparable test to the NR), aggression or boldness (David et al., 2012; Wuerz and Krüger, 2015).

In line with our results, temporal consistency in agonistic behavior has been previously found for other species (e.g., Australian lizard, Egernia whitii, While et al., 2010; bluefin killifish, Lucania goodei, McGhee and Travis, 2010; sheepshead swordtail, Xiphophorus birchmanni, Wilson et al., 2013). However, most of the behaviors, either aggressive or not, during the several sessions of territorial intrusions were found to be repeatable. Interestingly, a study in European seabass, Dicentrarchus labrax, performed coping screening tests in different contexts (isolation vs group) and repeated them within various time

Table 3

Effect of time and treatment (GnRH vs saline) on hormone levels (Physiological challenge experiment). Main effects (LMM), interactions, effect sizes and planned comparisons between the baseline and the other time points.

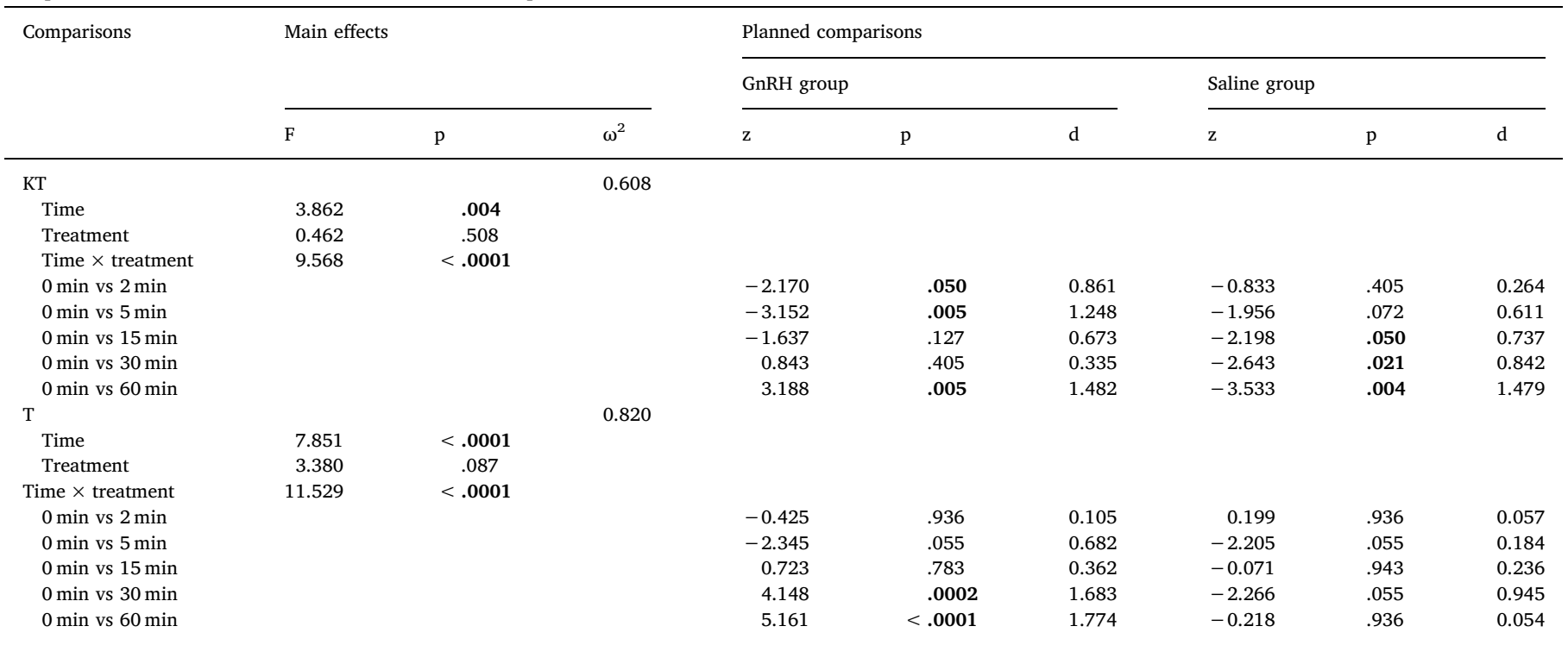

11-ketotestosterone (KT); testosterone (T); z-test estimate; $\omega^{2}$ : effect size estimate (omega squared); d: effect size estimate (Cohen's d); p: p-value after multiple comparison adjustment; statistically significant values are in bold. 
(a)

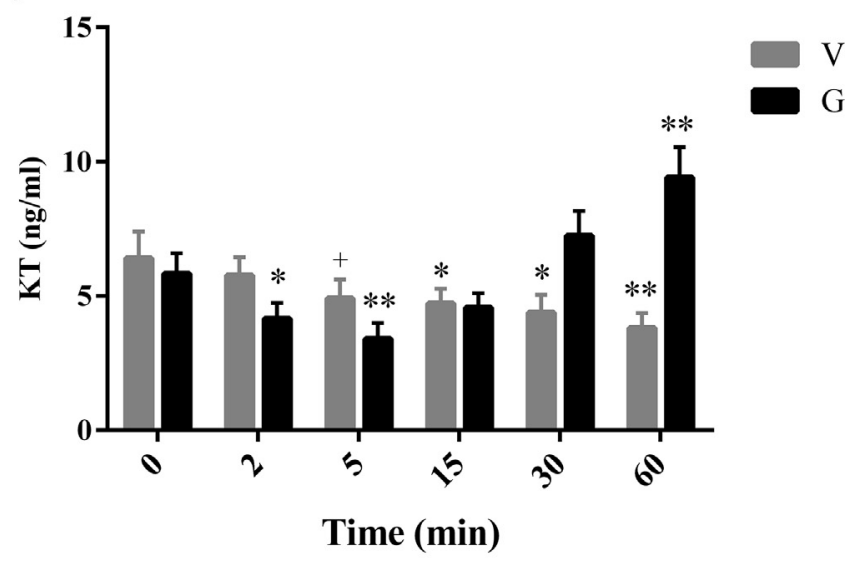

(b)

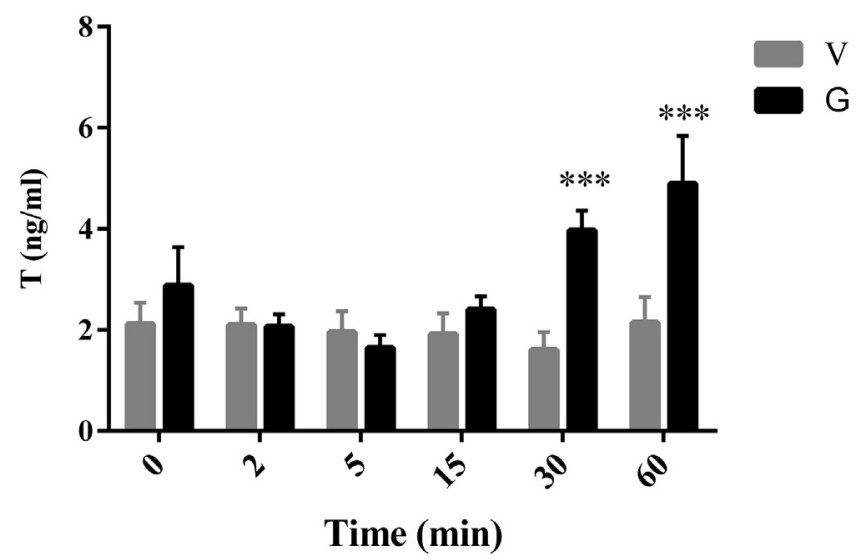

Fig. 5. Temporal pattern of the hormonal response of fish injected with vehicle (V) or with GnRH (G) in the Physiological challenge experiment. Values are mean \pm standard error of the mean (SEM). (a) 11-ketotestosterone (KT); (b) testosterone (T); * $\mathrm{p}<0.05 ; * * \mathrm{p}<0.01 ;{ }^{* * *} \mathrm{p}<0.001$.

intervals (up to 629 days) and found that, in opposition to individual tests, group-based tests were consistent across contexts and time (both short- and long-term) (Ferrari et al., 2015). Together these data suggest that social context promotes behavioral consistency at the individual level.

In our experiment we found a moderate negative correlation between aggressive behavior towards the intruder and exploration, that could be defined as a 'behavioral syndrome' (Bell, 2007; Sih et al., 2004) and could mean that the traits are regulated by a common neuroendocrine, genetic or neurobiological mechanism (Coppens et al., 2010; Sih et al., 2004).

The literature offers contradictory findings from several authors which attempted to explore the relationship between androgens and behavior, yet using baseline androgen levels (e.g. positive relation of exploration, boldness and aggression with $\mathrm{T}$ baseline levels in the mangrove rivulus, Kryptolebias marmoratus, Chang et al., 2012; positive relation between aggressive behavior and baseline $\mathrm{T}$ levels in male rats (Tryon Maze Dull S-3 rats), Schuurman, 1980; negative relation of exploration and boldness with $\mathrm{T}$ baseline levels in male great tits, Parus major, van Oers et al., 2011; negative relation of aggression with $\mathrm{T}$ baseline levels in male Australian lizards, E. whitii, While et al., 2010; no differences in $\mathrm{T}$ baseline levels between rats, Rattus norvegicus, selected for high or low levels of aggression, Everts et al., 1997). In the current study, individuals with a lower scope for KT response presented higher exploratory, activity, aggressiveness and body condition indices, in opposition to individuals with a higher scope of response. This set of results links relative levels (baseline versus physiological maximum), rather than absolute levels, of KT to exploration, activity and male-male aggressive behavior.

Finally, it is important to mention that other factors not addressed in this study may also contribute to the observed inter-individual variation in androgen responsiveness to social interactions, such as variation in steroid metabolizing enzymes in target cells (Cornil et al., 2012; Roselli et al., 2009) or in the number, affinity and specificity of androgen receptors (e.g. androgen receptors vary as a function of the social environment, Fuxjager et al., 2010). Future studies accounting for these factors are worth exploring.

The results obtained for the stimulation of the HPG axis by treating animals with GnRH suggest that the two waves of KT response could be mediated by different physiological mechanisms. The late $(90 \mathrm{~min})$ response of androgens to social interactions seems to agree with the temporal response of the HPG axis, whereas the short-response does not. Research in mammals has confirmed the existence of a direct neural pathway responsible for the regulation of gonadal functions, including testosterone secretion (Mayerhofer, 2007; Selvage et al., 2006). The involvement of this pathway in the androgen response to social stimuli has never been explored. However, it is a mechanism, independent of the pituitary release of gonadotropins into circulation and its transport to the gonads, which seems compatible with the quick response we observed. In the Nile tilapia (Oreochromis niloticus), a close related species, nerve bundles have been identified in the testis close to Leydig cells (Nakamura and Nagahama, 1995), which may be controlling androgen release. Further studies on this question are needed to assess if the early and late androgen responses are mediated by direct neural pathways vs. HPG axis.

In summary, we found that the androgen response to social challenges varies between males depending on their scope for response, and when present it presents two peaks that seem to be regulated by different physiological mechanisms: an early response probably mediated by direct neural pathways followed by a late endocrine response mediated by the HPG axis. We suggest that determining the temporal pattern of the androgen response to social interactions and considering individual variability may be the key to understanding contradictory results of the Challenge Hypothesis.

\section{Author contributions}

ASF and RFO designed the experiment; ASF and AR performed behavioral experiments; ASF processed samples and analyzed the data; ASF and RFO wrote the paper.

\section{Acknowledgements}

We thank Gonçalo Oliveira (ISPA) for useful advice on statistical analyses, Adelino Canário (University of Algarve) for helping with the in-house production of the reactive marker for the KT radioimmunoassay and all members of the Oliveira Lab for valuable discussions of this work. Much of this paper was written during the January 2019 ISPA Advanced Course in Biology and Animal Behavior (Scientific Writing) taught by Peter McGregor. RFO and ASF were supported by Fundação para a Ciência e a Tecnologia (grants EXCL/ BIA-ANM/0549/2012 and SFRH/BD/102892/2014, respectively).

\section{Data availability statement}

The datasets generated for this study are available on request to the corresponding author.

\section{Appendix A. Supplementary data}

Supplementary data to this article can be found online at https:// doi.org/10.1016/j.yhbeh.2020.104755. 


\section{References}

Aires, R.F., Oliveira, G.A., Oliveira, T.F., Ros, A.F.H., Oliveira, R.F., 2015. Dear enemies elicit lower androgen responses to territorial challenges than unfamiliar intruders in a cichlid fish. PLoS One 10, 1-11. https://doi.org/10.1371/journal.pone.0137705.

Alcazar, R.M., Becker, L., Hilliard, A.T., Kent, K.R., Fernald, R.D., 2016. Two types of dominant male cichlid fish: behavioral and hormonal characteristics. Biol. Open 5 , 1061-1071. https://doi.org/10.1242/bio.017640.

Amstislavskaya, T.G., Popova, N.K., 2004. Female-induced sexual arousal in male mice and rats: behavioral and testosterone response. Horm. Behav. 46, 544-550. https:// doi.org/10.1016/j.yhbeh.2004.05.010.

Apfelbeck, B., Goymann, W., 2011. Ignoring the challenge? Male black redstarts (Phoenicurus ochruros) do not increase testosterone levels during territorial conflicts but they do so in response to gonadotropin-releasing hormone. Proc. Biol. Sci. 278, 3233-3242. https://doi.org/10.1098/rspb.2011.0098.

Apfelbeck, B., Mortega, K.G., Kiefer, S., Kipper, S., Goymann, W., 2013. Life-history and hormonal control of aggression in black redstarts: blocking testosterone does not decrease territorial aggression, but changes the emphasis of vocal behaviours during simulated territorial intrusions. Front. Zool. 10, 8. https://doi.org/10.1186/17429994-10-8.

Arends, R.J., Mancera, J.M., Muñoz, J.L., Wendelaar Bonga, S.E., Flik, G., 1999. The stress response of the gilthead sea bream (Sparus aurata L.) to air exposure and confinement. J. Endocrinol. 163, 149-157. https://doi.org/10.1677/joe.0.1630149.

Baerends, G.P., Baerends-Van Roon, J.M., 1950. An Introduction to the Study of the Ethology of the Cichlid Fishes, Behaviour, Supplement. BRILL, Leiden.

Baird, T.A., Lovern, M.B., Shine, R., 2014. Heightened aggression and winning contests increase corticosterone but decrease testosterone in male Australian water dragons. Horm. Behav. 66, 393-400. https://doi.org/10.1016/j.yhbeh.2014.05.008.

Bell, A.M., 2007. Future directions in behavioural syndromes research. Proc. R. Soc. B Biol. Sci. 274, 755-761. https://doi.org/10.1098/rspb.2006.0199.

Benjamini, Y., Hochberg, Y., 1995. Controlling the false discovery rate: a practical and powerful approach to multiple testing. J. R. Stat. Soc. Ser. B. https://doi.org/10. $2307 / 2346101$

Bennett, A.F., 1987. Interindividual variability: an underutilized resource. New Dir. Ecol. Physiol. 147-169. https://doi.org/10.1002/mus.880150105.

Borg, B., 1994. Androgens in teleost fishes. Comp. Biochem. Physiol. Part C Comp. 109, 219-245. https://doi.org/10.1016/0742-8413(94)00063-G.

Caramachi, D., Carere, C., Sgoifo, A., Koolhaas, J.M., 2013. Neuroendocrine and autonomic correlates of animal personalities. Anim. Personal. Behav. Physiol. Evol. 1-22. https://doi.org/10.7208/chicago/9780226922065.001.0001.

Castanheira, M.F., Herrera, M., Costas, B., Conceição, L.E.C., Martins, C.I.M., 2013. Can we predict personality in fish? Searching for consistency over time and across contexts. PLoS One 8, 1-9. https://doi.org/10.1371/journal.pone.0062037.

Champagne, D.L., Hoefnagels, C.C.M., de Kloet, R.E., Richardson, M.K., 2010. Translating rodent behavioral repertoire to zebrafish (Danio rerio): relevance for stress research. Behav. Brain Res. 214, 332-342. https://doi.org/10.1016/j.bbr.2010.06.001.

Chang, C., Li, C.Y., Earley, R.L., Hsu, Y., 2012. Aggression and related behavioral traits: the impact of winning and losing and the role of hormones. Integr. Comp. Biol. 52, 801-813. https://doi.org/10.1093/icb/ics057.

Coppens, C.M., De Boer, S.F., Koolhaas, J.M., 2010. Coping styles and behavioural flexibility: towards underlying mechanisms. Philos. Trans. R. Soc. B Biol. Sci. 365, 4021-4028. https://doi.org/10.1098/rstb.2010.0217.

Cornil, C.A., Ball, G.F., Balthazart, J., 2012. Rapid control of male typical behaviors by brain-derived estrogens. Front. Neuroendocrinol. 33, 425-446. https://doi.org/10. 1016/j.yfrne.2012.08.003.

Creel, S., Wildt, D.E., Monfort, S.L., 1993. Aggression, reproduction, and androgens in wild dwarf mongooses: a test of the challenge hypothesis. Am. Nat. 141, 816-825. https://doi.org/10.1086/285509.

David, M., Auclair, Y., Cézilly, F., 2012. Assessing short- and long-term repeatability and stability of personality in captive zebra finches using longitudinal data. Ethology 118, 932-942. https://doi.org/10.1111/j.1439-0310.2012.02085.x.

de Assis, V.R., Navas, C.A., Mendonça, M.T., Gomes, F.R., 2012. Vocal and territorial behavior in the Smith frog (Hypsiboas faber): relationships with plasma levels of corticosterone and testosterone. Comp. Biochem. Physiol. - A Mol. Integr. Physiol. 163, 265-271. https://doi.org/10.1016/j.cbpa.2012.08.002.

Dingemanse, N.J., Dochtermann, N.A., 2013. Quantifying individual variation in behaviour: mixed-effect modelling approaches. J. Anim. Ecol. 82, 39-54. https://doi.org/ 10.1111/1365-2656.12013.

Everts, H.G.J., De Ruiter, A.J.H., Koolhaas, J.M., 1997. Differential lateral septal vasopressin in wild-type rats: correlation with aggression. Horm. Behav. 31, 136-144. https://doi.org/10.1006/hbeh.1997.1375.

Ferrari, S., Millot, S., Leguay, D., Chatain, B., Bégout, M.L., 2015. Consistency in European seabass coping styles: a life-history approach. Appl. Anim. Behav. Sci. 167, 74-88. https://doi.org/10.1016/j.applanim.2015.03.006.

Foo, J.T.W., Lam, T.J., 1993. Serum cortisol response to handling stress and the effect of cortisol implantation on testosterone level in the tilapia, Oreochromis mossambicus. Aquaculture 115, 145-158. https://doi.org/10.1016/0044-8486(93)90365-6.

Fryer, G., Iles, T.D., 1972. The Cichlid Fishes of the Great Lakes of Africa: Their Biology and Evolution. (Boyd, Edinburgh).

Fuxjager, M.J., Forbes-Lorman, R.M., Coss, D.J., Auger, C.J., Auger, A.P., Marler, C.A., 2010. Winning territorial disputes selectively enhances androgen sensitivity in neural pathways related to motivation and social aggression. Proc. Natl. Acad. Sci. U. S. A. 107, 12393-12398. https://doi.org/10.1073/pnas.1001394107.

Galhardo, L., Vitorino, A., Oliveira, R.F., 2012. Social familiarity modulates personality trait in a cichlid fish. Biol. Lett. 8, 936-938. https://doi.org/10.1098/rsbl.2012.0500.
Goymann, W., 2009. Social modulation of androgens in male birds. Gen. Comp. Endocrinol. 163, 149-157. https://doi.org/10.1016/j.ygcen.2008.11.027.

Goymann, W., Landys, M.M., Wingfield, J.C., 2007. Distinguishing seasonal androgen responses from male-male androgen responsiveness-revisiting the challenge hypoth esis. Horm. Behav. 51, 463-476. https://doi.org/10.1016/j.yhbeh.2007.01.007.

Goymann, W., Moore, I.T., Oliveira, R.F., 2019. Challenge hypothesis 2.0: a fresh look at an established idea. BioSci 69, 432-442. https://doi.org/10.1093/biosci/biz041.

Hannes, R.P., Franck, D., Liemann, F., 1984. Effects of rank-order fights n while-body and blood concentration of androgen and corticosteroids in the male swordfish (Xiphophorus helleri). Z. Tierpsychol. 65, 53-65.

Harrison, X.A., Donaldson, L., Correa-Cano, M.E., Evans, J., Fisher, D.N., Goodwin, C.E.D., Robinson, B.S., Hodgson, D.J., Inger, R., 2018. A brief introduction to mixed effects modelling and multi-model inference in ecology. PeerJ 6, e4794. https://doi. org $/ 10.7717 /$ peerj. 4794 .

Hau, M., Goymann, W., 2015. Endocrine mechanisms, behavioral phenotypes and plasticity: known relationships and open questions from new perspectives in behavioura development: adaptive shaping of behaviour over a lifetime? Hau Goymann Front. Zool. 12, 1-15. https://doi.org/10.1186/1742-9994-12-S1-S7.

Hirschenhauser, K., Oliveira, R.F., 2006. Social modulation of androgens in male vertebrates: meta-analyses of the challenge hypothesis. Anim. Behav. 71, 265-277. https://doi.org/10.1016/j.anbehav.2005.04.014.

Hirschenhauser, K., Winkler, H., Oliveira, R.F., 2003. Comparative analysis of male androgen responsiveness to social environment in birds: the effects of mating system and paternal incubation. Horm. Behav. 43, 508-519. https://doi.org/10.1016/ S0018-506X(03)00027-8.

Hirschenhauser, K., Taborsky, M., Oliveira, T., Canário, A.V.M., Oliveira, R.F., 2004. A test of the 'challenge hypothesis' in cichlid fish: simulated partner and territory intruder experiments. Anim. Behav. 68, 741-750. https://doi.org/10.1016/j.anbehav. 2003.12.015.

Hsu, Y., Earley, R.L., Wolf, L.L., 2011. Aggressive behaviour in fish: integrating information about contest costs. In: Brown, C., Laland, K., Krause, J. (Eds.), Fish Cognition and Behavior. Wiley-Blackwell, Oxford, UK, pp. 108-134. https://doi.org/ 10.1002/9781444342536.ch6.

Kamel, F., Frankel, A.I., 1978. Hormone release during mating in the male rat: time course, relation to sexual behavior, and interaction with handling procedures. Endocrinology 103, 2172-2179. https://doi.org/10.1210/endo-103-6-2172.

Kempenaers, B., Peters, A., Foerster, K., 2008. Sources of individual variation in plasma testosterone levels. Philos. Trans. R. Soc. B Biol. Sci. 363, 1711-1723. https://doi. org/10.1098/rstb.2007.0001.

Kime, D.E., Manning, N.J., 1982. Seasonal patterns of free and conjugated androgens in the brown trout Salmo trutta. Gen. Comp. Endocrinol. 48, 222-231. https://doi.org/ 10.1016/0016-6480(82)90020-X.

Kline, R.B., 1998. Methodology in the Social Sciences. Principles and Practice of Structural Equation Modeling. Guilford Press, New York.

Koolhaas, J.M., Korte, S.M., De Boer, S.F., Van Der Vegt, B.J., Van Reenen, C.G., Hopster, H., De Jong, I.C., Ruis, M. a W., Blokhuis, H.J., 1999. Coping styles in animals: current status in behavior and stress-physiology BT - Workshop on Ethology and Biomedical Science. Neurosci. Biobehav. Rev, 23, 925-935.

Kubokawa, K., Yoshioka, M., Iwata, M., 2001. Sex-specific cortisol and sex steroids responses in stressed sockeye Salmon during spawning period. Zool. Sci. 18, 947-955.

Lessells, C.M., Boag, P.T., 1987. Unrepeatable repeatabilities: a common mistake. Auk Ornithol. Adv. 104, 116-121. https://doi.org/10.2307/4087240.

Marler, C.A., Oyegbile, T.O., Plavicki, J., Trainor, B.C., 2005. Response to Wingfield's commentary on "a continuing saga: the role of testosterone in aggression.". Horm. Behav. 48, 256-258. https://doi.org/10.1016/j.yhbeh.2005.05.010.

Martins, C.I.M., Silva, P.I.M., Conceição, L.E.C., Costas, B., Höglund, E., Øverli, Ø., Schrama, J.W., 2011. Linking fearfulness and coping styles in fish. PLoS One 6. https://doi.org/10.1371/journal.pone.0028084.

Mayerhofer, A., 2007. Neuronal signaling molecules and Leydig cells. In: Payne, A.H., Hardy, M.P. (Eds.), Contemporary Endocrinology: The Leydig Cell in Health and Disease, Contemporary Endocrinology. Humana Press Inc, pp. 291-304. https://doi. org /10.1007/978-1-59745-453-7 20.

McGhee, K.E., Travis, J., 2010. Repeatable behavioural type and stable dominance rank in the bluefin killifish. Anim. Behav. 79, 497-507. https://doi.org/10.1016/j.anbehav. 2009.11.037.

Moore, I.T., Wada, H., Perfito, N., Busch, D.S., Hahn, T.P., Wingfield, J.C., 2004. Territoriality and testosterone in an equatorial population of rufous-collared sparrows, Zonotrichia capensis. Anim. Behav. 67, 411-420. https://doi.org/10.1016/j. anbehav.2003.03.021.

Nakamura, M., Nagahama, Y., 1995. Innervation of testes in the tilapia Oreochromis niloticus. Aquaculture 135, 41-49. https://doi.org/10.1016/0044-8486(95)01006-8.

Oliveira, R.F., 2004. Social modulation of androgens in vertebrates: mechanisms and function. In: Slater, P.J.B., Rosenblatt, J.S., Snowdown, C.T., Roper, T.J. (Eds.), Advances in the Study of Behavior. Academic Press, New York, pp. 165-239. https:// doi.org/10.1016/S0065-3454(04)34005-2.

Oliveira, R.F., Almada, V.C., 1996. Dominance hierarchies and social structure in captive groups of the Mozambique tilapia Oreochromis mossambicus (Teleostei, Cichlidae). Ethol. Ecol. Evol. 8. https://doi.org/10.1080/08927014.1996.9522934.

Oliveira, R.F., Almada, V.C., 1998. Mating tactics and male - male courtship in the lekbreeding cichlid Oreochromis mossambicus. J. Fish Biol. 52, 1115-1129.

Oliveira, R.F., Hirschenhauser, K., Carneiro, L.A., Canario, A.V.M., 2002. Social modulation of androgen levels in male teleost fish. Comp. Biochem. Physiol. - B Biochem. Mol. Biol. 132, 203-215. https://doi.org/10.1016/S1096-4959(01)00523-1.

Oliveira, R.F., Carneiro, L.A., Canário, A.V.M., 2005. Behavioural endocrinology: no hormonal response in tied fights. Nature 437, 207-208.

Oliveira, R.F., Silva, A., Canário, A.V.M., 2009. Why do winners keep winning? Androgen 
mediation of winner but not loser effects in cichlid fish. Proc. R. Soc. B 276, 2249-2256. https://doi.org/10.1098/rspb.2009.0132.

$\emptyset$ verli, Ø., Sørensen, C., Pulman, K.G.T., Pottinger, T.G., Korzan, W., Summers, C.H., Nilsson, G.E., 2007. Evolutionary background for stress-coping styles: relationships between physiological, behavioral, and cognitive traits in non-mammalian vertebrates. Neurosci. Biobehav. Rev. 31, 396-412. https://doi.org/10.1016/j.neubiorev. 2006.10.006.

Oyegbile, T.O., Marler, C.A., 2005. Winning fights elevates testosterone levels in California mice and enhances future ability to win fights. Horm. Behav. 48, 259-267. https://doi.org/10.1016/j.yhbeh.2005.04.007.

Réale, D., Reader, S.M., Sol, D., McDougall, P.T., Dingemanse, N.J., 2007. Integrating animal temperament within ecology and evolution. Biol. Rev. 82, 291-318. https:// doi.org/10.1111/j.1469-185X.2007.00010.x.

Ros, A.F.H., Vullioud, P., Bruintjes, R., Vallat, A., Bshary, R., 2014. Intra- and interspecific challenges modulate cortisol but not androgen levels in a year-round territorial damselfish. J. Exp. Biol. 217, 1768-1774. https://doi.org/10.1242/jeb.093666.

Roselli, C.E., Liu, M., Hurn, P.D., 2009. Brain aromatization: classic roles and new perspectives. Semin. Reprod. Med. https://doi.org/10.1055/s-0029- 1216274.

Schuurman, T., 1980. In: McConnell, P.S., Boer, G.J., Romijn, H.J., Van De Poll, N.E., Corner, M.A.B.T.-P. (Eds.), Hormonal Correlates of Agonistic Behavior in Adult Male Rats. Elsevier, pp. 415-420. https://doi.org/10.1016/S0079-6123(08)60079-5. B.R.

Selvage, D.J., Parsons, L., Rivier, C., 2006. Role played by brainstem neurons in regulating testosterone secretion via a direct neural pathway between the hypothalamus and the testes. Endocrinology 147, 3070-3075. https://doi.org/10.1210/en.20051358.

Sih, A., Bell, A., Johnson, J.C., 2004. Behavioral syndromes: an ecological and evolutionary overview. Trends Ecol. Evol. 19, 372-378. https://doi.org/10.1016/j.tree. 2004.04.009.

Silva, S.S. De, 1985. Body condition and nutritional ecology of Oreochromis Mossambicus (Pisces, Cichlidae) populations of man-made lakes in Sri-Lanka. J. Fish Biol. 27, 621-633. https://doi.org/10.1111/j.1095-8649.1985.tb03207.x.

Silva, P.I.M., Martins, C.I.M., Engrola, S., Marino, G., Øverli, Ø., Conceição, L.E.C., 2010. Individual differences in cortisol levels and behaviour of Senegalese sole (Solea senegalensis) juveniles: evidence for coping styles. Appl. Anim. Behav. Sci. 124, 75-81. https://doi.org/10.1016/j.applanim.2010.01.008.
Stoffel, M.A., Nakagawa, S., Schielzeth, H., 2017. rptR: repeatability estimation and variance decomposition by generalized linear mixed-effects models. Methods Ecol. Evol. 8, 1639-1644. https://doi.org/10.1111/2041-210X.12797.

Team, R.C, 2015. R: A Language and Environment for Statistical Computing.

van Oers, K., Buchanan, K.L., Thomas, T.E., Drent, P.J., 2011. Correlated response to selection of testosterone levels and immunocompetence in lines selected for avian personality. Anim. Behav. 81, 1055-1061. https://doi.org/10.1016/j.anbehav.2011. 02.014.

Virgin, C.E., Sapolsky, R.M., 1992. Styles of male social behavior and their endocrine correlates among high-ranking wild baboons. Am. J. Primatol. 28, 231-250. https:// doi.org/10.1002/ajp.1350280402.

While, G.M., Isaksson, C., McEvoy, J., Sinn, D.L., Komdeur, J., Wapstra, E., Groothuis, T.G.G., 2010. Repeatable intra-individual variation in plasma testosterone concentration and its sex-specific link to aggression in a social lizard. Horm. Behav. 58, 208-213. https://doi.org/10.1016/j.yhbeh.2010.03.016.

Williams, T.D., 2008. Individual variation in endocrine systems: moving beyond the "tyranny of the Golden mean". Philos. Trans. R. Soc. B Biol. Sci. 363, 1687-1698. https://doi.org/10.1098/rstb.2007.0003.

Wilson, A.J., Grimmer, A., Rosenthal, G.G., 2013. Causes and consequences of contest outcome: aggressiveness, dominance and growth in the sheepshead swordtail, Xiphophorus birchmanni. Behav. Ecol. Sociobiol. 67, 1151-1161. https://doi.org/10. 1007/s00265-013-1540-7.

Wingfield, J.C., Hegner, R.E., Dufty Jr., A.M., Ball, G.F., 1990. The "challenge hypothesis": theoretical implications for patterns of testosterone secretion, mating systems, and breeding strategies. Am. Nat. 136, 829. https://doi.org/10.1086/285134.

Wingfield, J.C., Lynn, S., Soma, K.K., 2001. Avoiding the "costs" of testosterone: ecological bases of hormone-behavior interactions. Brain Behav. Evol. 57, 239-251. https://doi.org/10.1159/000047243.

Wuerz, Y., Krüger, O., 2015. Personality over ontogeny in zebra finches: long-term repeatable traits but unstable behavioural syndromes. Front. Zool. 12. https://doi.org/ 10.1186/1742-9994-12-S1-S9.

Young, K., Gobrogge, K., Liu, Y., Wang, Z., 2011. The neurobiology of pair-bonding: insight from a socially monogamus rodent. Front. Neuroendocrinol. 32, 53-69. https:/ doi.org/10.1016/j.yfrne.2010.07.006.THE. 